\title{
Analisis Framing Zong Dang Pan dan Gerald M. Kosicki Pada Pemberitaan Pembagian Vaksin Covid-19 di DetikNews
}

\author{
Aldo Gunawan*, Hendra Setiawan \\ Universitas Singaperbangsa Karawang, Indonesia \\ *Coresponding Author: 1710631080023@student.unsika.ac.id
}

Article History:

Received 2021-12-02

Revised 2022-01-11

Accepted 2022-02-01

DOI:

10.31949/educatio.v8i1.1791

\begin{abstract}
Advances in information and communication technology have made online media more popular than conventional media because of the ease of accessing them. In their reporting, each is always influenced by the ideology, power and interests of the media owners. In this study, it is discussed about the analysis of framing in the news of an online media in detikNews which contains the distribution of vaccines in the city of Semarang as many as 5,450 vaccines that will be distributed in the city of Semarang are not enough for the community, especially for health workers, there are 15 bealth workers in the city. Therefore, the mayor of Semarang gave several stages for the distribution of the vaccine before it reached the general public. This study aims to conduct an analysis based on a qualitative descriptive method in which the overall content refers to the content analysis carried out using the framing approach of Zhong Dang Pan and Gerald M. Kosicki. This study uses a qualitative method based on words, both written and spoken, from visible actions. The results showed that detikNews in reporting a news using the inverted pyramid technique. Where the main discussion topics discussed in the news are stored at the beginning of the news. In addition, there are some data obtained by news writers from the statements of the sources to serve as data sources. The structure of the news uses $5 \mathrm{~W}+1 \mathrm{H}$ and there are not many quotes made by the sources

Keywords: framing analysis; news; detiknews; online media
\end{abstract}

\section{PENDAHULUAN}

Teknologi komunikasi semakin berkembang dari hari ke hari. Salah satunya yang berkembang sangat pesat yaitu hadirnya news media seperti situs berita online. Hal ini tidak terlepas dari kebutuhan masyarakat 
akan informasi sebagai bagian dari gaya hidup. Situs berita online sebenernya memiliki karakteristik seperti media massa lain yaitu sama-sama menyediakan informasi dan berita-berita yang actual (Suprobo et al, 2016). Informasi yang diangkat dalam media massa sangat beragam seperti, permasalah sosial, budaya, ekonomi, politik, gender, dan masih banyak lainnya yang menyangkut aspek kehidupan manusia.

Dalam melaporkan berita, masing-masing media memiliki kemampuan dalam mengkonstruk dan membingkai sebuah realitas. Oleh sebab itu, peristiwa yang sama berpotensi dikonstruksi berbeda oleh beberapa media massa. Jurnalis atau wartawan bisa jadi mempunyai pandangan dan konsepsi berbeda dalam melihat suatu peristiwa, yang diwujudkan dalam teks berita. Dalam media, penulisan suatu berita dikonstruksikan berdasarkan realitas. Namun terkadang penulisan berita dikonstruksikan tidak sesuai dengan realita yang ada (Fianto \& Aminulloh, 2015). Sebuah berita terkadang dikonstruksikan tidak sesuai dengan hasil yang konstruksinya. Dalam artian, berita yang disampaikan dalam media ternyata menyimpan subjektivitas penulis dan tidak netral. Berita yang dimuat di media adalah hasil bentukan dari pengetahuan dan pikiran dari wartawan. Artinya bahwa sebelum memuat suatu berita, berita tersebut sudah diolah sesuai dengan kepentingan dan ideologi media.

Media mengkonstruksi melalui pemberitaan yang muncul dengan pemilihan sudut pandang, penentuan sumber berita, dan mendefinisikan actor serta adanya satu peristiwa (Boer et al, 2020; Fadli \& Novita, 2021; Najihah, 2021). Bahasa menjadi unsur utama untuk menceritakan realitas, mengkonsep sesuatu dan menarasikan sehingga ada nilai tertentu yang dipahami dan dimaknai (Damayanti et al, 2016). Media massa menjadi sarana untuk menyebarkan pesan/informasi kepada masyarakat (Masyhuri, 2016). Seiring perkembangan informasi yang sedang berkembang saat ini menjadikan peran media massa semakin dibutuhkan dan berita pun menjadi sangat penting bagi masyarakat. Informasi yang dikonsumsi setiap hari oleh masyarakat banyak didapatkan dari media massa. Karena media massa menyajikan peristiwa-peristiwa seputar kehidupan masyarakat baik yang bersifat nasional maupun internasional, sehingga dengan adanya berita manusia mengetahui, memahami, dan mengerti segala sesuatu yang terjadi di sekitar dan di dunia.

Setiap media massa mempunyai karakteristik penyampaian berita yang berbeda, baik itu media cetak, elektronik, maupun media online. Media online yang tumbuh sangat pesat, sangat berperan penting pada pemberitaan setiap informasi (Setiawan \& Nulhakim, 2019). Media yang tidak hanya dijadikan sebagai sarana penyampaian informasi, namun juga dijadikan sebagai alat untuk menggiring opini publik sesuai dengan tujuan media massa tersebut. Dengan adanya pemberitaan di media online tidak jarang menimbulkan opini publik yang beragam (Indrawan, 2017).

Media massa seperti detikNews yaitu media online berita yang disajikan dalam media massanya tersebut membuat daya tarik yang mampu mengundang keingintahuan pembaca atau masyarakat. Media online detikNews yang ditampilkan dapat berupa peristiwa, kejadian, opini, ide, dan sebagainya. Berita juga dapat menarik perhatian pembaca karena peristiwa yang diangkat merupakan berita luar biasa, penting, atau mempengaruhi kehidupan masyarakat. Serta mengundang pembaca karena melibatkan emosi, empati, dan simpati.

Dengan adanya pemberitaan di media online tidak jarang menimbulkan opini publik yang beragam. Khususnya, pemberitaan yang disajikan oleh detikNews, selalu menarik untuk menjadi bahan kajian. Pada penelitian ini, pemberitaan tentang 5.450 vaksin covid-19 untuk Nakes Semarang yang akan dibagi kan mulai di bulan januari ini sangat menarik perhatian warga dimana vaksin yang belum diuji cobakan malah akan dibagikan. Bagaimana media mengkontruksi sebuah berita yang akan disampaikan pada masyarakat. Hal-hal apa saja yang akan ditonjolkan atau dihilangkan. Dalam, media detikNews yang dikaji dalam penulisan ini, yaitu berita pada edisi 8 Januari 2021 mengenai pemberitaan 5.450 vaksin untuk Nakes Semarang yang akan dibagi mulai Januari.

Dalam penulisan ini penulis bertujuan untuk mengetahui bagaimana cara media detikNews mengolah sebuah berita yang akan disebar-luaskan dan framing-framing apa saja yang akan di hilangkan dan ditonjolkan oleh media detikNews untuk menyampaikan sebuah informasi yang realita. Banyak penelitian terdahulu yang juga melakukan analisis framing terhadap suatu pemberitaan di media online, seperti penelitian yang dilakukan Setiawan \& Nulhakim (2019) pada pemberitaan kasus dugaan ujaran kebencian habib bahar bin smith kepada 
presiden joko widodo, penelitian Ibad (2016) pada Website Pemerintah Kota Samarinda, Damayanti et al. (2016) pada majalah tempo, penelitian Sinaga \& Nasution (2016) pada kompas.com, penelitian Fortuna (2020) pada media online Tribunnews.com dan Suara.com, penelitian yang dilakukan Pinontoan \& Wahid (2020) pada Harian kompas.com dan jawapos.com, dan penelitian yang dilakukan Gaio Diahloka (2015) pada media vivanews.co.id dan detiknews.com. Penelitian ini mencoba melakukan analisis framing dengan menggunakan pendekatan framing Zhong Dang Pan dan Gerald M. Kosicki pada media detiknews tentang pemberitaan pembagian vaksin Covid-19 bagi tenaga kesehatan yang terbit pada edisi 08 Januari 2021.

\section{METODE PENELITIAN}

Dalam penelitian ini, metode yang digunakan lebih mengarah kepada metode kualitatif. Hal tersebut diungkapkan menurut Moleong (2005), penelitian kualitatif adalah penelitian yang bermaksud untuk memahami fenomena tentang apa yang dialami oleh subjek penelitian misalnya perilaku, persepsi, motivasi, tindakan, dll secara holistic, dan dengan cara deskripsi dalam bentuk kata-kata dan bahasa, pada suatu konteks khusus yang alamiah dan dengan memanfaatkan berbagai metode ilmiah, sedangkan menurut Sugiyono (2016) yang menyatakan bahwa metode penelitian kualitatif ini merupakan metode yang berlandaskan pada filsafat postpotivisme, digunakan untuk meneliti pada kondisi obyek yang alamiah yang mana peneliti sebagai intrumen kunci hingga pada hasilnya yang menekankan pada makna dari pada generalisasi. Selain itu, penelitian ini bersifat deskripsi dimana hasilnya penelitian berorientasi pada isi. Hasil analisis atau data yang dapat disajikan/dipaparkan secara deskriptif dalam bentuk narasi. Isi dari penelitian ini yaitu analisis framing dari pemberitaan tentang 5.450 vaksin covid-19 untuk Nakes Semarang dibagi mulai januari. Pada penelitian ini berita diunduh dari dan bersumber dari media online detikNews edisi 08 Januari 2021.

Sumber data yang akan digunakan dalam penelitian ini adalah primer dan sekunder. Data primer didapat dengan cara mengumpulkan dan mendokumentasikan teks berita mengenai pembagian vaksin pada tenaga kesehatan di detiknews.com edisi 8 januari 2021. Sedangkan data sekunder akan dilakukan dengan cara mencari data dari berbagai sumber seperti buku, internet, tesis, jurnal yang akan dijadikan sebagai bahan acuan untuk penelitian. Analisis data yang digunakan dalam penelitian ini analisis teks media dengan metode analisis framing menggunakan pendekatan model Zhong Dang Pan dan Gerald M. Kosicki.

\section{HASIL DAN PEMBAHASAN}

Penelitian ini bertujuan untuk melakukan analisis framing dari pemberitaan tentang 5.450 vaksin covid19 untuk Nakes Semarang dibagi mulai januari. Pada penelitian ini berita diunduh dari dan bersumber dari media online detikNews edisi 08 Januari 2021 yang berjudul "5.450 Vaksin COVID-19 untuk Nakes Semarang Dibagi Mulai Januari” dan ditulis oleh Abu Ubaidillah.

Hasil analisis framing pada berita " 5.450 vaksin COVID-19 untuk Nakes Semarang dibagi mulai januari”, adalah sebagai berikut:

1) Struktur Sintaksis

Dalam berita 5.450 vaksin Covid-19 untuk Nakes Semarang dibagi mulai januari ini menggunakan sebuah struktur piramida terbalik, dimana informasi yang penting terdapat di tengah berita dimna 5.450 vaksin ini akan diberikan kepada semua tenaga Kesehatan namun vaksin tersbut tidak cukup untuk di bagikan ke 15 ribu orang tenaga kesehatan sebelum dibagikan kepada masyarakat semarang karena ada 4 tahap sebelum dibagikan nya vaksin ke masyarakat, yang pertama kepada tenaga Kesehatan, tahap kedua kepada petugas pelayanan publik, tahap ketiga kepada masyarakat rentan atau lansia, dan tahap keempat kepada masyarakat umum dan pelaku ekonomi. kemudian di lengkapi oleh kutipan dari narasumber sebagai informan agar memperjelas sebuah berita

2) Aspek Skrip

Skrip yang digunakan pada berita diatas telah memuat $5 \mathrm{~W}+1 \mathrm{H}$ secara keseluruhan. Lihat tabel 1 untuk rincian strukturnya. 
Tabel 1. Struktur $5 \mathrm{~W}+1 \mathrm{H}$ pada berita

\begin{tabular}{cl}
\hline Komponen & \multicolumn{1}{c}{ Uraian berita } \\
\hline WHAT & 5.450 vaksin Covid-19 untuk Nakes Semarang dibagi mulai januari \\
WHO & Walikoa Semarang dan Pemkot Semarang \\
WHERE & Semarang \\
WHEN & 08 Januari 2021 \\
& Pemerintah Semarang telah menyediakan dana BTT yang sudah dicadangkan \\
WHY & mencapi Rp.50 miliar rupiah, tapi mereka masih mencari tahu, apakah vaksin- \\
& vaksin itu selain yang sudah diploting dari pusat, dapat melakukan pembelian \\
& mandiri \\
& pembagian vaksin COVID-19 untuk masyarakat Semarang direncanakan \\
& dengan merujuk Kemenkes RI yang membagi dalam 4 tahap. Tahap \\
& pertama untuk tenaga kesehatan diupayakan pada Januari-April 2021, \\
& kemudian tahap kedua untuk petugas pelayanan publik juga pada Januari- \\
& April 2021.
\end{tabular}

HOW

Setelah itu tahap ketiga dan keempat direncanakan berlangsung pada April 2021 - Maret 2022. Tahap ketiga dikhususkan untuk kelompok masyarakat rentan seperti lansia, sedangkan tahap keempat diperuntukkan kepada masyarakat umum dan pelaku ekonomi.

\section{3) Struktur Tematik}

Dalam struktur tematik teks berita di atas berisi beberapa paragraf singkat yang diikuti dengan kutipan pernyataan dari narasumber untuk mendukung teks berita. Tema yang ditekankan yaitu akan dibagikan nya vaksin sebanyak 5.450 di daerah Semarang pada januari dimana vaksin ini akan di berikan kepada masyarakat Semarang dengan diberikan 4 tahapan pemberian vaksin sebelum ke masyarakat umum. Tahap pertama akan diberikan kepada tenaga kesehatan, tahap kedua diberikan kepada petugas pelayanan publik, tahap ketiga dikhusus untuk kelompok masyarakat rentan seperti lansia, tahap keempat kepada masyarakat umum dan pelaku ekonomi

\section{4) Struktur Retoris}

Dalam berita yang disajikan oleh detikNews ini tidak banyak menggunakan kutipan dari narasumber, dan banyak menggunakan paragraf sebagai pengantar isi berita. Namun, ada kata lain yang dituliskan yaitu kata "tak menampik" yang artinya "tidak menolak" dimana menampik berasal dari kata dasar "tampik" karena "menampik" dapat menyatakan suatu tindakan, keberadaa, pengalaman, atau pengetian.

Temuan yang diperoleh dari penelitian ini diantaranya bahwa detikNews dalam memberitakan suatu berita menggunakan teknik piramida terbalik. Di mana topik pembahasan utama yang dibahas dalam berita tersebut disimpan dibagian awal berita. Kemudian, penentuan tema dengan mengangkat masalah yang ada dibutuhkan oleh pembaca, selain itu aspek $5 \mathrm{~W}+1 \mathrm{H}$ pun tidak tertinggal dalam berita tersebut yang mana memuat secara keseluruhan dan struktur berita. Teknik ini juga digunakan dalam pemberitaan kasus dugaan ujaran kebencian habib bahar bin smith kepada presiden joko widodo (Setiawan \& Nulhakim, 2019), dan pemberitaan banjir oleh humas di website pemerintah Kota Samarinda (Ibad, 2016). Dalam berita yang berjudul "5.450 Vaksin COVID-19 untuk Nakes Semarang Dibagi Mulai Januari” tidak banyak menggunakan pengutipan kepada narasumber atau informan yang ada hanya sebuah penjelasan paragraf yang dijadikan sumber data atau pelengkap isi berita. Pada umumnya media memuat sebuah artikel berita yang didalamnya memuat kaidah keberimbangan, pada media online prinsip keberimbangan berita tidak muncul dalam satu berita tetapi dalam prinsip update, sepotong-sepotong atau dipecah-pecah. 


\section{KESIMPULAN}

Hasil penelitian ini menunjukkan bahwa dalam menyampaikan berita yang berjudul " 5.450 Vaksin COVID-19 untuk Nakes Semarang Dibagi Mulai Januari", detikNews menggunakan teknik piramida terbalik. Di mana topik pembahasan utama yang dibahas dalam berita tersebut disimpan dibagian awal berita. Kemudian, penentuan tema dengan mengangkat masalah yang ada dibutuhkan oleh pembaca, selain itu aspek $5 \mathrm{~W}+1 \mathrm{H}$ pun tidak tertinggal dalam berita tersebut yang mana memuat secara keseluruhan dan struktur berita.

\section{DAFTAR PUSTAKA}

Boer, K. M., Pratiwi, M. R., \& Muna, N. (2020). Analisis framing pemberitaan generasi milenial dan pemerintah terkait Covid-19 di media online. Communicatus: Jumal Ilmu Komunikasi, 4(1), 85-104.

Damayanti, S., Mayangsari, I. D., \& Putra, D. K. S. (2016). Analisis framing robert n. Entman atas pemberitaan reklamasi teluk jakarta di majalah tempo. eProceedings of Management, 3(3).

Fadli, K., \& Novita, P. (2021). Analisis Framing Media Online Tentang Pandemi Covid-19 (Studi Kasus Covid-19 Pada Media Online Tribun News. com dan Kepri. co. id Edisi Bulan Maret s/d Juni 2020). Jurnal Purnama Berazam, 2(2), 172-200.

Fianto, L., \& Aminulloh, A. (2015). Analisis Framing Berita Kasus Korupsi Ketua Mahkamah Konstitusi Akil Mochtar di Vivanews. com dan Detik. com. JISIP: Jurnal Ilmu Sosial dan Ilmu Politik, 3(1).

Fortuna, A. (2020). Analisis framing terhadap pemberitaan pelaku kasus perundungan Audrey di Tribunnews. com dan Suara. com. Communique, 1(1).

Gaio, A. M. S., \& Diahloka, C. (2015). Analisis Framing Robert Entman Pada Pemberitaan Konflik Kpk Vs Polri Di Vivanews. Co. Id Dan Detiknews. Com. JISIP: Jurnal Ilmu Sosial dan Ilmu Politik, 4(3).

Ibad, K. (2016). Analisis Framing Berita Banjir Oleh Humas Di Website Pemerintah Kota Samarinda. Journal Ilmu Komunikasi, 4(3), 520-34.

Indrawan, R. M. J. (2017). Dampak komunikasi politik dan opini publik terhadap perilaku masyarakat. WACANA: Jurnal Ilmiah Ilmu Komunikasi, 16(2), 171-179.

Masyhuri, K. (2016). Media Massa Sebagai Wujud Reformasi dan Pengaruhnya Terhadap Masyarakat Islam. Dakwatuna: Jurnal Dakwah dan Komunikasi Islam, 2(2), 29-48.

Moleong, L. (2005). Metodologi Penelitian Kualitatif. Bandung: PT Remaja Rosdakarya

Najihah, U. (2021). Pemberitaan terkait sikap generasi millenial mengenai Covid-19 di media online: Analisis framing pemberitaan pada media online CNNINDONESLA. com, Liputan 6. com, dan Kompas. com (Doctoral dissertation, UIN Sunan Gunung Djati Bandung).

Pinontoan, N. A., \& Wahid, U. (2020). Analisis Framing Pemberitaan Banjir Jakarta Januari 2020 Di Harian Kompas. Com Dan Jawapos. Com. Komuniti: Jurnal Komunikasi dan Teknologi Informasi, 12(1), 11-24.

Setiawan, H., \& Nulhakim, L. (2019). Analisis Framing Zong Dang Pan dan Gerald M. Kosicki pada Pemberitaan Kasus Dugaan Ujaran Kebencian Habib Bahar Bin Smith kepada Presiden Joko Widodo. Jurnal Artikula, 2(1), 48-53.

Sinaga, K. C. S., \& Nasution, B. (2016). Analisis Framing Pemberitaan Bom Sarinah di Kompas. com dan Merdeka. com (Doctoral dissertation, Riau University).

Sugiyono. (2016). Metode Penelitian Kuantitatif, kualitatif dan ReD. Bandung: PT Alfabet

Suprobo, T., Siahainenia, R., \& Sari, D. (2016). Analisis Framing Media Online Dalam Pemberitaan Profil Dan Kebijakan Menteri Susi Pudjiastuti (Studi Pada Situs Berita Detik.com, Kompas.com dan Antaranews.com periode Oktober - Desember 2014). Cakrawala Jurnal Penelitian Sosial, 5(1).. 